\title{
Changes of cardiac troponin I and hypersensitive C-reactive protein prior to and after treatment for evaluating the early therapeutic efficacy of acute myocardial infarction treatment
}

\author{
LI WANG $^{1,2^{*}}$, BING LIAO $^{3 *}$, JIAN YU $^{1,4^{*}}$, LING CHEN $^{1}$, XIAOZHONG CAI $^{1}$, \\ LI LIU $^{1}$, KAIWEN HOU ${ }^{5}$ and MINGHAO ZHANG ${ }^{1}$
}

\author{
${ }^{1}$ Lab Teaching and Management Center, Chongqing Medical University, Chongqing 400016; \\ ${ }^{2}$ Department of Gynecology and Obstetrics, The Second Affiliated Hospital of Chongqing Medical University, \\ Chongqing 400010; ${ }^{3}$ Department of Laboratory Medicine, The Ninth People's Hospital of Chongqing, Chongqing 400700; \\ ${ }^{4}$ Department of Anesthesiology, The First Affiliated Hospital of Chongqing Medical University, Chongqing 400016; \\ ${ }^{5}$ Outpatient Department, The General Hospital of Western Theater Command, Chengdu, Sichuan 610083, P.R. China
}

Received February 4, 2019; Accepted October 9, 2019

DOI: $10.3892 / \mathrm{etm} .2019 .8206$

\begin{abstract}
The present study aimed to evaluate the utility of the extent of change $(\mathrm{C})$ and change rate $(\mathrm{Cr})$ of cardiac troponin $\mathrm{I}(\mathrm{cTnI})$ and hypersensitive $\mathrm{C}$-reactive protein (hs-CRP) prior to and after treatment in evaluating the early therapeutic efficacy of acute myocardial infarction (AMI) treatment. A total of 145 patients with AMI who received regular MI treatment were enrolled in the present study. Patients were divided into the effective group and the ineffective group based on the early therapeutic efficacy. The values of two parameters, namely the serum levels of cTnI and hs-CRP, were collected prior to and after AMI treatment. Data were analyzed by using the t-test, Chi-squared test, logistic regression and receiver operating characteristic (ROC) curve analysis. Compared with those in the ineffective group, the values of cTnI and hs-CRP after treatment $\left[\mathrm{cTnI}_{\text {(post) }}\right.$ and hs-CRP $\left.\mathrm{P}_{\text {(post) }}\right]$, as well as their $\mathrm{C}$ and $\mathrm{Cr}$ values, were significantly decreased in the effective group $(\mathrm{P}<0.01)$. Furthermore, the positive rates (PR) of $\mathrm{cTnI}_{(\text {post })}$, hs-CRP (post) $(\mathrm{cTnI}+\mathrm{hs}-\mathrm{CRP})_{(\mathrm{post})}, \mathrm{C}_{(\mathrm{cTnI})}, \mathrm{C}_{(\mathrm{hs}-\mathrm{CRP})}$ and $\mathrm{C}_{(\mathrm{cTnI}+\mathrm{hs}-\mathrm{CRP})}$ were significantly lower in the effective group compared with those in the ineffective group $(\mathrm{P}<0.01)$. It was indicated that hs-CRP $\mathrm{P}_{\text {(post) }}$ and $\mathrm{C}_{(\mathrm{hs}-\mathrm{CRP})}$, as well as the PR-cTnI $\mathrm{f}_{\text {(post) }}$ and the PR-C $\mathrm{C}_{(\mathrm{cTnI})}$, may be used as independent factors for early therapeutic efficacy evaluation $(\mathrm{P}<0.05)$. In addition, the area under the ROC curve, as well as the associated sensitivity and specificity analysis for
\end{abstract}

Correspondence to: Mr. Minghao Zhang, Lab Teaching and Management Center, Chongqing Medical University, 1 Yi Xueyuan Road, Chongqing 400016, P.R. China

E-mail: zhangminghao@cqmu.edu.com.cn

*Contributed equally

Key words: cardiac troponin I, hypersensitive C-reactive protein, acute myocardial infarction, extent of change, change rate
$\mathrm{cTnI}_{\text {(post) }}$, hs- $\mathrm{CRP}_{\text {(post) }}, \mathrm{C}_{\text {(cTnI or hs-CRP) }}$ and $\mathrm{Cr}_{\text {(cTnI or hs-CRP) }}$, all indicated that these parameters were able to distinguish between the effective and the ineffective groups. The present study revealed that compared with the $\mathrm{CTnI}_{\text {(post) }}$ and hs-CRP ${ }_{\text {(post) }}$, the $\mathrm{C}$ and the $\mathrm{Cr}$ of cTnI and hs-CRP may have enhanced value for evaluating the early therapeutic efficacy of AMI treatment.

\section{Introduction}

Acute myocardial infarction (AMI) has become the leading cause of death worldwide, and it is also the most serious type of coronary artery disease (1). Regarding the treatment of this disease, early evaluation of treatment effects and outcomes is required in order to select the patient's further individualized treatment (2).

Cardiac troponin I (cTnI), the standard marker for myocardial necrosis (3), is one of the important diagnostic indicators for patients with AMI (3). However, due to a delayed release of cTnI, its sensitivity within the first hour of AMI is not sufficient for diagnosis, which is therefore being referred to as the 'troponin-blind period' (3). The acute phase of the inflammatory response is an important step in the development of AMI (4). Hypersensitive C-reactive protein (hs-CRP) is a highly sensitive acute inflammatory protein produced by the liver (5), which may be used as an independent risk factor for predicting adverse cardiovascular events. A number of studies have indicated an increase in serum hs-CRP in patients with AMI $(6,7)$.

To date, only a few studies have assessed the changes of cTnI and hs-CRP in patients after treatment for AMI. Koskinas et al (8) reported that in patients with ST segment elevation MI, hs-CRP was significantly decreased after intensive statin treatment compared with that prior to treatment, suggesting that the curative effect may be assessed by using the indexes of absolute values or the extent of change of hs-CRP. In the present study, the utility of the absolute values of cTnI and hs-CRP, as well as changes of cTnI and hs-CRP, prior to and after treatment [extent of change $(C)$ and change rate $(\mathrm{Cr})]$ in evaluating the early treatment efficacy for AMI was investigated. 


\section{Materials and methods}

Patients. A total of 145 patients with AMI treated at the Ninth People's Hospital of Chongqing between December 2011 and January 2015 were enrolled in the present study. The diagnostic criteria for AMI applied were the World Health Organization's 'Clinical Diagnostic Criteria for Coronary Heart Disease', 2003 edition (9). The inclusion criteria were as follows: i) Patients with 'non-ST segment-elevation MI' at first onset or hospitalized within $12 \mathrm{~h}$ of onset; and ii) patients with a similar first-course treatment strategy. Patients with comorbidities, including diabetes, malignant tumors, chronic respiratory diseases and coagulopathy, and those who received special or long-term treatments, were excluded. The present study was approved by the Ethics Committee of the Chongqing Health Economics Association (Chongqing, China). Informed consent was obtained from each patient.

AMI treatments, including dilation of blood vessels, thrombolytic therapy, regulation of heart rhythm and anti-shock therapy (Table I), were performed in strict accordance with the Guidelines for the Treatment of AMI (2001 edition by the Chinese Medical Association Cardiovascular Society) (10). The first phase of AMI treatment lasted for 7-10 days. Two indicators, including cTnI and hs-CRP, were respectively measured within $2 \mathrm{~h}$ of hospitalization (the start value) and in the early morning of the last day of the first treatment (the end value). Effective treatment in the first phase of treatment was defined as follows: i) Electrocardiogram indicated that the ST segment or the T wave returned to normal and ii) the symptoms of chest tightness or pain disappeared. Patients were divided into the effective group $(n=69)$ and the ineffective group $(n=76)$ based on the early therapeutic efficacy (10). All participants were followed up every three months for one year post-discharge. They were followed up by phone or outpatient visit. The mortality and re-infarction rates were recorded.

Detection of cTnI and hs-CRP. The serum cTnI was detected using the Architect i4000SR plus automated immunoassay system (Abbott Diagnostics). The serum hs-CRP was measured with a Hitachi automatic biochemical analyzer 7600 (Hitachi, Ltd.). The measurements of cTnI and hs-CRP were strictly in accordance with the instructions of their corresponding kits, which were the Cardiac Troponin I kit (Abbott Ireland Diagnostics Division) and the Hypersensitive C-reactive Protein kit (Maccura Biotechnology Co.). According to the instructions, when cTnI was $<0.3 \mathrm{ng} / \mathrm{ml}$ and hs-CRP was $<8 \mathrm{mg} / \mathrm{l}$, the test result was considered negative; otherwise, it was considered positive.

Definition. C represents the extent of change prior to and after treatment, while $\mathrm{Cr}$ represents the change rate after treatment. The formula for calculating $\mathrm{C}$ or $\mathrm{Cr}$ of cTnI was as follows:

$$
C_{(\mathrm{cTnI})}=\mathrm{cTnI}_{(\text {post })}-\mathrm{cTnI}_{(\text {pre })} \text {. }
$$

If $\mathrm{C}_{(\mathrm{cTnI})} \geq 0, \mathrm{Cr}_{(\mathrm{cTnI})}=\mathrm{C}_{(\mathrm{cTnI})} / \mathrm{cTnI}_{(\text {post })} ;$ if $\mathrm{C}_{(\mathrm{cTnI})}<0$, $\mathrm{Cr}_{(\mathrm{cTnI})}=\mathrm{C}_{(\mathrm{cTnI})} / \mathrm{CTnI}_{(\mathrm{pre})}$.

$\mathrm{cTnI}_{(\text {post })}$ is the value of cTnI after treatment, while $\mathrm{cTnI}_{\text {(pre) }}$ is the value of cTnI prior to treatment. $\mathrm{C}_{(\mathrm{cTnI})}$ is the extent of change of cTnI after treatment and $\mathrm{Cr}_{(\mathrm{CTnI})}$ is the change rate of cTnI.

Similarly, $\mathrm{C}_{(\mathrm{hs}-\mathrm{CRP})}$ and $\mathrm{Cr}_{(\mathrm{hs}-\mathrm{CRP})}$ were calculated as follows.

$$
\mathrm{C}_{\text {(hs-CRP) }}=\text { hs- } \mathrm{CRP}_{\text {(post) }} \text {-hs- } \mathrm{CRP}_{\text {(pre) }} \text {. }
$$

If $\mathrm{C}_{\text {(hs-CRP) }} \geq 0, \mathrm{Cr}_{\text {(hs-CRP) }}=\mathrm{C}_{\text {(hs-CRP) }} / \mathrm{hs}-\mathrm{CRP}_{\text {(post) }}$; if $\mathrm{C}_{\text {(hs-CRP) }}<0$, $\mathrm{Cr}_{\text {(hs-CRP) }}=\mathrm{C}_{(\text {hs-CRP) }} / \mathrm{hs}-\mathrm{CRP}_{\text {(pre) }}$.

If the value of cTnI or hs-CRP was greater than the upper limit of its reference value, it was considered as positive; otherwise, it was defined as negative. If $\mathrm{cTnI}_{(\text {post })}$ and hs-CRP (post) $_{\text {w }}$ were positive, the combined detection of $\mathrm{cTnI}_{\text {(post) }}$ and hs-CRP $\mathrm{P}_{\text {(post) }}$ was positive; otherwise, it was defined as negative. If the value of $\mathrm{C}_{(\mathrm{CTnI})}$ or $\mathrm{C}_{\text {(hs-CRP) }}$ was no less than zero, it was defined as positive; otherwise, it was defined as negative. If $\mathrm{C}_{(\mathrm{CTnI})}$ and $\mathrm{C}_{\text {(hs-CRP) }}$ were positive, the combined detection of $\mathrm{C}_{(\mathrm{CTnI})}$ and $\mathrm{C}_{(\mathrm{hs}-\mathrm{CRP})}$ was defined as positive; otherwise, it was defined as negative (2).

Statistical analysis. The data were analyzed by using SPSS 17.00 (SPSS Inc.). The non-parametric independent-samples t-test was used to analyze the differences in cTnI, hsCRP, C and $\mathrm{Cr}$ between the effective group and the ineffective group. The chi-squared test and the odds ratio analysis were used to determine the difference in the positive rate (PR) of $\mathrm{cTnI}_{(\mathrm{post})}$, hs-CRP ${ }_{(\text {post })},(\mathrm{cTnI}+\mathrm{hs}-\mathrm{CRP})_{(\mathrm{post})}, \mathrm{C}_{(\mathrm{cTnI})}, \mathrm{C}_{\text {(hs-CRP) }}$ and $\mathrm{C}_{(\mathrm{cTnI} I \mathrm{ths}-\mathrm{CRP})}$ between the effective and ineffective groups. Multivariate logistic regression analysis was performed by using four models. The treatment groups (the effective or the ineffective group) were used as dependent variables and five indicators (sex, age, treatment days and the value of cTnI and hs-CRP) were used as independent variables. Model I was based on the values of $\mathrm{cTnI}_{\text {(post) }}$ and hs-CRP $\mathrm{C}_{\text {(post) }}$; Model II was based on the PR of $\mathrm{cTnI}_{\text {(post) }}$ and hs-CRP (post) $_{\text {; }}$ Model III was based on the $\mathrm{C}_{(\mathrm{cTnI})}$ and $\mathrm{C}_{(\mathrm{hs}-\mathrm{CRP})}$; Model IV was based on the PR of $\mathrm{C}_{\text {(cTnI) }}$ and $\mathrm{C}_{\text {(hs-CRP) }}$. Receiver operating characteristic (ROC) curves for $\mathrm{cTnI}_{(\text {post) }}$ and hs-CRP $\mathrm{P}_{(\text {post) }}, \mathrm{C}_{(\mathrm{cTnI})}, \mathrm{C}_{(\mathrm{hs}-\mathrm{CRP})}, \mathrm{Cr}_{\text {(cTnI) }}$ and $\mathrm{Cr}_{(\mathrm{hs}-\mathrm{CRP})}$ to distinguish between the effective and ineffective groups were respectively analyzed. Based on the corresponding thresholds, the area under the ROC curve (AUC) for $\mathrm{cTnI}_{\text {(post) }}$ and hs- $\mathrm{CRP}_{\text {(post) }}, \mathrm{C}_{\text {(cTnI) }}, \mathrm{C}_{\text {(hs-CRP) }}, \mathrm{Cr}_{\text {(cTnI) }}$ and $\mathrm{Cr}_{\text {(hs-CRP) }}$, as well as the sensitivities and specificities, were respectively calculated. $\mathrm{P}<0.05$ was considered to indicate statistical significance.

\section{Results}

Basic clinical characteristics. The characteristics of patients of the effective and ineffective groups were compared. No significant differences in age $(72.30 \pm 10.998$ years vs. $72.96 \pm 11.384$ years), duration of treatment $(7.97 \pm 4.759$ days vs. $6.93 \pm 3.689$ days) and sex ratio $(42 / 27$ male vs. $49 / 27$ female) were identified between the effective group and the ineffective group ( $\mathrm{P}>0.05)$. Following 12 months after discharge, valid follow-up data were obtained for 33 patients in the effective group, where 3 incidences of AMI and 2 mortalities occurred, and for 41 patients in the ineffective group, including 5 incidences of AMI and 3 mortalities. The mortality and re-infarction rates were not significantly different between the two groups. Therefore, 
Table I. Treatment of patients and the proportion of patients in the effective and ineffective groups.

\begin{tabular}{lccc}
\hline Group & $\begin{array}{c}\text { Dilation of } \\
\text { blood vessels }\end{array}$ & $\begin{array}{c}\text { Thrombolytic } \\
\text { therapy }\end{array}$ & $\begin{array}{c}\text { Regulation of } \\
\text { heart rhythm }\end{array}$ \\
\hline Effective group $(\mathrm{n}=69)$ & $69(100)$ & $49(71.01)$ & $69(100)$ \\
Ineffective group $(\mathrm{n}=76)$ & $76(100)$ & $58(76.32)$ & $76(100)$ \\
Total $(\mathrm{n}=145)$ & $145(100)$ & $107(73.79)$ & $145(100)$
\end{tabular}

Values are expressed as $\mathrm{n}(\%)$.

Table II. Patient characteristics.

\begin{tabular}{lccc}
\hline Characteristic & Effective group $(\mathrm{n}=69)$ & Ineffective group $(\mathrm{n}=76)$ & P-value \\
\hline Age (years) & $72.30 \pm 10.998$ & $72.96 \pm 11.384$ & 0.882 \\
Sex (male/female) & $42 / 27$ & $49 / 27$ & 0.732 \\
Duration of treatment (days) & $7.97 \pm 4.759$ & $6.93 \pm 3.689$ & 0.166 \\
\hline
\end{tabular}

there were no significant differences between the two groups regarding their baseline characteristics and follow-up data (Table II).

Significant differences in $\mathrm{cTnI}_{(\text {post })}$, hs- $\mathrm{CRP}_{(\mathrm{post})}, \mathrm{C}_{(\mathrm{cTnI})}$, $\mathrm{C}_{(\mathrm{hs}-\mathrm{CRP})}, \mathrm{Cr}_{(\mathrm{cTnI})}$ and $\mathrm{Cr}_{(\mathrm{hs}-\mathrm{CRP})}$ between the effective and ineffective groups. To identify any differences of $\mathrm{cTnI}_{\text {(pre/post) }}$, hs- $\mathrm{CRP}_{\text {(pre/post) }}, \mathrm{C}_{\text {(cTnI or hs-CRP) }}$ and $\mathrm{Cr}_{\text {(cTnI or hs-CRP) }}$ between the effective group and the ineffective group, non-parametric independent-samples t-tests were performed. Prior to treatment for AMI, there were no significant differences in the levels of $\mathrm{cTnI}_{(\text {pre })}$ and hs- $\mathrm{CRP}_{(\text {pre) }}$ between the two groups (P>0.05; Table III). However, after treatment for AMI, significant differences in the levels of $\mathrm{cTnI}_{(\text {post) }}$ and hs-CRP $\mathrm{P}_{\text {(post) }}$ were determined between the effective group and the ineffective group. Similarly, the levels of $\mathrm{C}_{(\mathrm{cTnI})}, \mathrm{C}_{(\mathrm{hs}-\mathrm{CRP})}, \mathrm{Cr}_{(\mathrm{cTnI})}$ and $\mathrm{Cr}_{\text {(hs-CRP) }}$ were also significantly different between the two groups $(\mathrm{P}<0.01)$. After one course of treatment, six indicators, including $\mathrm{cTnI}_{(\text {post })}$, hs-CRP $\mathrm{Cpost}_{\text {(p) }}, \mathrm{C}_{(\mathrm{cTnI})}, \mathrm{C}_{(\mathrm{hs}-\mathrm{CRP})}, \mathrm{Cr}_{(\mathrm{cTnI})}$ and $\mathrm{Cr}_{\text {(hs-CRP), }}$ were significantly improved in the patients.

Significant differences in $P R-c T n I_{(p o s t)}, P R-h s-C R P_{(\text {post })}$, $P R-(c T n I+h s-C R P)_{(\text {post })}$ as well as $P R-C_{(c T n I)}, P R-C_{(h s-C R P)}$ and $P R-C_{(c T n I+h s-C R P)}$ between the effective and the ineffective group. To test whether the PR of the various indicators differs between the effective and the ineffective group, chi-squared tests were performed. The PR-cTnI (post) , PR-hs-CRP (post), PR-(cTnI+hs-CRP) $)_{(\text {post })}$, as well as PR-C $\mathrm{C}_{(\mathrm{cTnI})}, \mathrm{PR}-\mathrm{C}_{(\mathrm{hs}-\mathrm{CRP})}$ and PR- $\mathrm{C}_{(\mathrm{cTnI}+\mathrm{hs}-\mathrm{CRP})}$, were significantly different between the effective group and the ineffective group $(\mathrm{P}<0.01$; Table IV). The odds ratios to indicate effective treatment for the $\mathrm{PR}-\mathrm{C}_{(\mathrm{cTnI})}$, PR- $\mathrm{C}_{(\mathrm{hs}-\mathrm{CRP})}$ and particularly the PR-C $\mathrm{C}_{(\mathrm{cTnI}+\mathrm{hs}-\mathrm{CRP})}$ were much higher than those for the PR-cTnI ${ }_{(\text {post })}$, PR-hs-CRP ${ }_{\text {(post) }}$ and PR-(cTnI+hs-CRP) $)_{(\text {post })}$. Thus, the use of PR-C $\mathrm{C}_{(\mathrm{cTnI})}$ and PR-C $\mathrm{C}_{(\mathrm{hs}-\mathrm{CRP})}$ may be better than that of PR-cTnI $\mathrm{I}_{\text {(post) }}$ and PR-hs-CRP ${ }_{\text {(post) }}$ for evaluating the early efficacy of AMI treatment. Furthermore, the combination of PR-C $\mathrm{C}_{(\mathrm{cTnI})}$ and
PR- $\mathrm{C}_{(\mathrm{hs}-\mathrm{CRP})}$ had the best value in evaluating the early efficacy of AMI treatment.

Efficacy evaluation by four models. In order to explore the impact of various factors on the early efficacy of AMI treatment, multivariate logistic regression analysis was performed. The groups (effective and ineffective group) were used as the dependent variable and the five indicators [sex, age, treatment

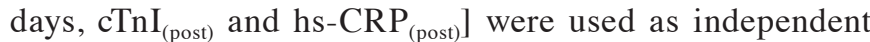
variables. As presented in Table V, the total effective rate in Model I was $75.5 \%$, and it was indicated that the hs-CRP $\mathrm{P}_{\text {(post) }}$ may be used as an independent factor for efficacy evaluation in Model I $(\mathrm{P}<0.05)$. The total effective rate in Model II was $73.5 \%$ and according to this model, the positive rate of $\mathrm{cTnI}_{\text {(post) }}$ may be used as an independent factor for evaluation of the treatment efficacy $(\mathrm{P}<0.05)$. The total effective rate in Model III was $75.5 \%$ and it was indicated that $\mathrm{C}_{(\mathrm{hs}-\mathrm{CRP})}$ may be used as an independent factor for efficacy evaluation $(\mathrm{P}<0.05)$. The total effective rate in Model IV was $83.7 \%$ and according to this model, the PR- $\mathrm{C}_{(\mathrm{cTnI})}$ may be used as an independent factor for evaluation of efficacy $(\mathrm{P}<0.01)$. The analysis suggested that, among the various factors that may be indicative of the early efficacy of AMI treatment, hsCRP (post) $_{\text {(hs-CRP) }}, \mathrm{CR}_{\text {-cTnI }}$ (post) and $\mathrm{PR}-\mathrm{C}_{(\mathrm{cTnI})}$ were the best indicators.

ROC analysis of $c \operatorname{TnI}_{(p o s t)}, C_{(c T n I)}$ and $\mathrm{Cr}_{(c T n I)}$ to determine the early efficacy of AMI therapy. The ROC curves for $\mathrm{cTnI}_{(\mathrm{post})}, \mathrm{C}_{(\mathrm{cTnI})}$ and $\mathrm{Cr}_{(\mathrm{cTnI})}$ to distinguish between the effective and ineffective groups were separately analyzed. For $\mathrm{cTnI}_{\text {(post) }}$, the AUC was $0.775(95 \%$ CI: $0.695-0.854, \mathrm{P}<0.001)$ at the best cut-off value of $2.459 \mathrm{ng} / \mathrm{ml}$. The corresponding sensitivity was $70.4 \%$ and the specificity was 80.9\%. For $\mathrm{C}_{(\mathrm{cTnI})}$, the AUC was 0.826 (95\% CI: 0.755-0.898, $\mathrm{P}<0.001)$ at the best cut-off value of $0.001 \mathrm{ng} / \mathrm{ml}$. The corresponding sensitivity was $73.2 \%$ and the specificity was $89.7 \%$. For $\mathrm{Cr}_{(\mathrm{cTnI})}$, the AUC was 0.851 (95\% CI: 0.786-0.916, $\left.\mathrm{P}<0.001\right)$ and the cut-off value was $-17.725 \%$. The corresponding sensitivity was $77.5 \%$ and the specificity was $83.8 \%$ (Fig. 1; Table VI). 
Table III. cTnI and hs-CRP prior to and after treatment in the effective and ineffective groups, as well as the extent of change and the rate of change.

\begin{tabular}{|c|c|c|c|c|}
\hline Parameter/group & Number of patients & Mean \pm SD & Median & P-value \\
\hline $\operatorname{cTnI}_{(\mathrm{pre})}$ & & & & 0.094 \\
\hline Effective group & 68 & $10.75 \pm 15.17$ & 2.78 & \\
\hline Ineffective group & 72 & $7.93 \pm 13.18$ & 0.93 & \\
\hline$c \operatorname{TnI} I_{\text {(post) }}$ & & & & $<0.001$ \\
\hline Effective group & 68 & $2.92 \pm 7.28$ & 0.49 & \\
\hline Ineffective group & 72 & $15.81 \pm 16.93$ & 9.42 & \\
\hline hs-CRP $($ pre) & & & & 0.972 \\
\hline Effective group & 23 & $40.65 \pm 63.46$ & 9.7 & \\
\hline Ineffective group & 31 & $37.54 \pm 44.84$ & 14.3 & \\
\hline hs-CRP ${ }_{\text {(post) }}$ & & & & $<0.001$ \\
\hline Effective group & 23 & $15.60 \pm 22.57$ & 4.3 & \\
\hline Ineffective group & 31 & $55.00 \pm 47.49$ & 51.5 & \\
\hline $\mathrm{C}_{(\mathrm{cTnI})}$ & & & & $<0.001$ \\
\hline Effective group & 68 & $-7.83 \pm 11.80$ & -1.96 & \\
\hline Ineffective group & 72 & $7.88 \pm 18.29$ & 2.03 & \\
\hline $\mathrm{C}_{(\mathrm{hs}-\mathrm{CRP})}$ & & & & $<0.001$ \\
\hline Effective group & 23 & $-25.05 \pm 54.75$ & -7.7 & \\
\hline Ineffective group & 31 & $17.45 \pm 32.50$ & 7.6 & \\
\hline $\mathrm{Cr}_{(\mathrm{cTnI})}$ & & & & $<0.001$ \\
\hline Effective group & 68 & $-54.29 \pm 50.28$ & -70.69 & \\
\hline Ineffective group & 72 & $34.53 \pm 63.38$ & 55.41 & \\
\hline $\mathrm{Cr}_{\text {(hs-CRP) }}$ & & & & $<0.001$ \\
\hline Effective group & 23 & $-31.82 \pm 57.85$ & -52.54 & \\
\hline Ineffective group & 31 & $39.71 \pm 44.09$ & 46.08 & \\
\hline
\end{tabular}

$\mathrm{SD}$, standard deviation; hs-CRP, hypersensitive C-reactive protein; $\mathrm{C}$, extent of change; $\mathrm{Cr}$, change rate; post, post-treatment; pre, pre-treatment; cTnI, cardiac troponin I.

Similarly, the ROC curves for hs- $\mathrm{CRP}_{(\text {post }}, \mathrm{C}_{(\mathrm{hs}-\mathrm{CRP})}$ and $\mathrm{Cr}_{\text {(hs-CRP) }}$ were also drawn (Fig. 2). For hs-CRP (post) $_{\text {, }}$, the AUC was 0.785 (95\% CI: $0.660-0.911, \mathrm{P}<0.001)$ at the best cut-off value of $14.850 \mathrm{mg} / \mathrm{l}$; the sensitivity was $74.2 \%$ and the specificity was $78.3 \%$. For $\mathrm{C}_{(\mathrm{hs}-\mathrm{CRP})}$, the AUC was 0.837 (95\% CI: $0.727-0.946, \mathrm{P}<0.001)$ at the cut-off value of $1.750 \mathrm{mg} / \mathrm{l}$; the sensitivity and specificity were 74.2 and $87.0 \%$, respectively. For $\mathrm{Cr}_{\text {(hs-CRP) }}$, the AUC was 0.826 (95\% CI: 0.708-0.945, $\mathrm{P}<0.001)$ at the cut-off value of $-13.565 \%$, with a sensitivity of $87.1 \%$ and a specificity of $73.9 \%$. The AUCs of those above-mentioned indicators ranged from 0.775 to 0.851 , indicating that they all had a certain predictive effect. Of note, the AUCs of those six indicators exhibited a trend: $\mathrm{Cr}_{(\mathrm{cTnI})}>$ $\mathrm{C}_{(\mathrm{hs}-\mathrm{CRP})}>\mathrm{Cr}_{(\mathrm{hs}-\mathrm{CRP})}=\mathrm{C}_{(\mathrm{cTnI})}>\mathrm{hs}-\mathrm{CRP}_{(\text {post })}>\mathrm{cTnI} \mathrm{(post}_{\text {, }}$, indicating that the $\mathrm{C}$ and $\mathrm{Cr}$ values of the two indicators were more suitable for assessment of the therapeutic effect than their absolute values.

\section{Discussion}

In the present study, the utility of cTnI and hs-CRP in evaluating the early efficacy of AMI treatment was evaluated. The levels of cTnI and hs-CRP were measured in patients with AMI treated between 2011 and 2015. The results suggested that after treatment, the levels of cTnI and hs-CRP, as well as their $\mathrm{C}$ and $\mathrm{Cr}$, were markedly decreased in the effective group $(\mathrm{P}<0.01)$. The hs- $\mathrm{CRP}_{\text {(post) }}$ and $\mathrm{C}_{(\mathrm{hs}-\mathrm{CRP})}$, as well as the PR-cTnI $\mathrm{(post)}_{\text {and PR- }}$ (cTnI) , may be used as independent factors for evaluating the early therapeutic efficacy $(\mathrm{P}<0.05)$. The present study also confirmed that the $\mathrm{C}$ and $\mathrm{Cr}$ of cTnI and hs-CRP had better sensitivity and specificity for assessing the early treatment efficacy of AMI than the absolute values.

AMI is the most severe manifestation of coronary artery disease (1), mostly due to atherosclerotic plaque rupture. Atherosclerosis is thought to be caused by lipids invading the arterial wall, which deposit between smooth muscle cells, collagen or elastin fibers, and stimulate fibrous tissue proliferation (11). Once plaques rupture, platelets bind to collagen through cell surface receptors to accelerate thrombus formation, promote platelet recruitment and adhesion, and aggravate coronary stenosis (12). In the clinic, patients with MI commonly present with chest pain and acute circulatory dysfunction, and the condition seriously endangers the life of aged individuals affected (2). 
Table IV. Odds of the positive rate to indicate effective treatment compared between the effective group and the ineffective group.

\begin{tabular}{|c|c|c|c|c|c|}
\hline Parameter/status & Effective group, n (\%) & Ineffective group, n (\%) & P-value & Odds ratio & $95 \% \mathrm{CI}$ \\
\hline PR-cTnI (post) & & & 0.008 & 2.728 & $1.277-5.83$ \\
\hline $\mathrm{N}$ & $27(65.85)$ & $14(34.15)$ & & & \\
\hline $\mathrm{P}$ & $41(41.41)$ & $58(58.59)$ & & & \\
\hline PR-hs-CRP ${ }_{\text {(post) }}$ & & & 0.002 & 6.481 & $1.908-22.014$ \\
\hline $\mathrm{N}$ & $14(70.00)$ & $6(30.00)$ & & & \\
\hline $\mathrm{P}$ & $9(26.47)$ & $25(73.53)$ & & & \\
\hline PR-(cTnI+hs-CRP) $)_{(\text {post })}$ & & & 0.001 & 6.063 & $1.935-18.994$ \\
\hline $\mathrm{N}$ & $32(62.75)$ & $19(37.25)$ & & & \\
\hline $\mathrm{P}$ & $5(21.74)$ & $18(78.26)$ & & & \\
\hline $\mathrm{PR}-\mathrm{C}_{(\mathrm{cTnI})}$ & & & $<0.001$ & 20.921 & $8.464-51.711$ \\
\hline $\mathrm{N}$ & $60(75.95)$ & $19(24.05)$ & & & \\
\hline $\mathrm{P}$ & $8(13.11)$ & $53(86.89)$ & & & \\
\hline PR-C $\mathrm{C}_{\text {(hs-CRP) }}$ & & & $<0.001$ & 11.806 & $3.255-42.821$ \\
\hline $\mathrm{N}$ & $17(73.91)$ & $6(26.09)$ & & & \\
\hline $\mathrm{P}$ & $6(19.35)$ & $25(80.65)$ & & & \\
\hline PR-C $\mathrm{C}_{(\mathrm{cTnI} I+\mathrm{hs}-\mathrm{CRP})}$ & & & $<0.001$ & 58.095 & $7.340-459.787$ \\
\hline $\mathrm{N}$ & $61(74.39)$ & $21(25.61)$ & & & \\
\hline $\mathrm{P}$ & $1(4.76)$ & $20(95.24)$ & & & \\
\hline
\end{tabular}

Odds ratio $=(\mathrm{N}$ of the effective group $\mathrm{x} \mathrm{P}$ of the ineffective group $) /(\mathrm{N}$ of the ineffective group $\mathrm{x}$ P of the effective group $)$. $\mathrm{P}$, number of positives; $\mathrm{N}$, number of negatives; PR, positive rate; hs-CRP, hypersensitive C-reactive protein; C, extent of change; post, post-treatment; cTnI, cardiac troponin I.

Table V. Effects of sex, age and treatment days, as well as parameters associated with cTnI and hs-CRP, on the clinical outcomes of patients.

\begin{tabular}{|c|c|c|c|c|c|c|c|c|c|c|c|c|}
\hline \multirow[b]{2}{*}{ Variable } & \multicolumn{3}{|c|}{ Model I } & \multicolumn{3}{|c|}{ Model II } & \multicolumn{3}{|c|}{ Model III } & \multicolumn{3}{|c|}{ Model IV } \\
\hline & B & Wals F & P-value & $\mathrm{B}$ & Wals F & P-value & $\mathrm{B}$ & Wals F & P-value & B & Wals F & P-value \\
\hline Sex (male, female) & 0.742 & 0.946 & 0.331 & 0.832 & 1.199 & 0.274 & 0.797 & 1.075 & 0.300 & 1.993 & 2.833 & 0.092 \\
\hline Age (years) & -0.018 & 0.281 & 0.596 & 0.001 & 0.001 & 0.981 & -0.019 & 0.300 & 0.584 & 0.017 & 0.128 & 0.721 \\
\hline Treatment days & -0.061 & 0.547 & 0.459 & -0.096 & 1.406 & 0.236 & -0.088 & 1.179 & 0.278 & -0.062 & 0.257 & 0.612 \\
\hline $\mathrm{cTnI}_{\text {(post) }}$ & 0.063 & 3.567 & 0.059 & - & - & - & - & - & - & - & - & - \\
\hline $\mathrm{hsCRP}_{\text {(post) }}$ & 0.031 & 6.066 & 0.014 & - & - & - & - & - & - & - & - & - \\
\hline PR-cTnI ${ }_{(\text {post })}(\mathrm{P}, \mathrm{N})$ & - & - & - & 1.802 & 5.469 & 0.019 & - & - & - & - & - & - \\
\hline PR-hs-CRP ${ }_{\text {(post) }}(\mathrm{P}, \mathrm{N})$ & - & - & - & 1.436 & 3.269 & 0.070 & - & - & - & - & - & - \\
\hline $\mathrm{C}_{(\mathrm{cTnI})}$ & - & - & - & - & - & - & 0.036 & 1.668 & 0.197 & - & - & - \\
\hline $\mathrm{C}_{\text {(hs-CRP) }}$ & - & - & - & - & - & - & 0.037 & 5.222 & 0.022 & - & - & - \\
\hline $\mathrm{PR}-\mathrm{C}_{(\mathrm{cTnI})}(\mathrm{P}, \mathrm{N})$ & - & - & - & - & - & - & - & - & - & 4.239 & 8.997 & 0.003 \\
\hline PR-C $\mathrm{C}_{(\mathrm{hs}-\mathrm{CRP})}(\mathrm{P}, \mathrm{N})$ & - & - & - & - & - & - & - & - & - & 0.629 & 0.321 & 0.571 \\
\hline
\end{tabular}

PR, positive rate; hs-CRP, hypersensitive C-reactive protein; C, extent of change; post, post-treatment; cTnI, cardiac troponin I; P, positive; $\mathrm{N}$, negative.

Current methods for assessing the early treatment effects of AMI are not sensitive and comprise serum enzymes including aspartate aminotransferase (AST), lactate dehydrogenase (LDH) and their isoenzymes $(13,14)$. Since AST and $\mathrm{LDH}$ are distributed in numerous organs throughout the body, their diagnostic specificity is poor (15). Creatine kinase isoenzymes (CK-MB) may reflect the subtle changes of myocardial injury; thus, the abnormal increase of serum CK-MB may be used for early prediction or therapeutic evaluation of myocardial injury; however, its specificity is 
Table VI. ROC analysis of $\mathrm{cTnI}_{(\mathrm{post})}, \mathrm{C}_{(\mathrm{cTnI})}, \mathrm{Cr}_{(\mathrm{cTnI})}, \mathrm{hs}-\mathrm{CRP}_{(\mathrm{post})}, \mathrm{C}_{\text {(hs-CRP) }}$ and $\mathrm{Cr}_{(\mathrm{hs}-\mathrm{CRP})}$ to determine the early efficacy of AMI therapy.

\begin{tabular}{lcccccc}
\hline Groups & AUC & $95 \% \mathrm{CI}$ & P-value & $\begin{array}{c}\text { Best cut } \\
\text { off value }\end{array}$ & $\begin{array}{c}\text { Corresponding } \\
\text { sensitivity (\%) }\end{array}$ & $\begin{array}{r}\text { Corresponding } \\
\text { specificity (\%) }\end{array}$ \\
\hline cTnI $_{\text {(post) }}$ & 0.775 & $0.695-0.854$ & $<0.001$ & $2.459 \mathrm{ng} / \mathrm{ml}$ & 70.4 & 80.9 \\
$\mathrm{C}_{\text {(CTnI) }}$ & 0.826 & $0.755-0.898$ & $<0.001$ & $0.001 \mathrm{ng} / \mathrm{ml}$ & 73.2 & 89.7 \\
$\mathrm{Cr}_{\text {(cTnl) }}$ & 0.851 & $0.786-0.916$ & $<0.001$ & $-17.725 \%$ & 77.5 & 83.8 \\
hs-CRP $_{\text {(post) }}$ & 0.785 & $0.660-0.911$ & $<0.001$ & $14.85 \mathrm{mg} / 1$ & 74.2 & 87.3 \\
$\mathrm{C}_{\text {(hs-CRP) }}$ & 0.837 & $0.727-0.946$ & $<0.001$ & $1.75 \mathrm{mg} / 1$ & 87.2 & 73.9 \\
$\mathrm{Cr}_{\text {(hs-CRP) }}$ & 0.826 & $0.708-0.945$ & $<0.001$ & $-13.565 \%$ & 87.1 & \\
\hline
\end{tabular}

AUC, area unter the curve; hs-CRP, hypersensitive C-reactive protein; C, extent of change; post, post-treatment; cTnI, cardiac troponin I.

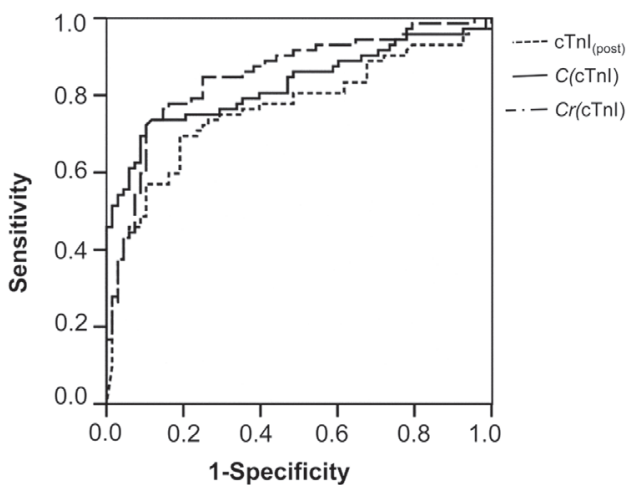

Figure 1. Receiver operating characteristic curves for $\mathrm{cTnI}_{(\mathrm{post})}, \mathrm{C}(\mathrm{cTnI})$ and $\mathrm{Cr}(\mathrm{cTnI})$ to differentiate between the effective and ineffective groups. C, extent of change; $\mathrm{Cr}$, change rate; cTnI, cardiac troponin I; post, post-treatment.

low due to its expression in multiple tissues (16). In addition, the degree of ST segment changes in the aVF lead has certain significance in the prognostication of patients with AMI, but its sensitivity is not high either (17).

hs-CRP, an acute-phase reactant, is significantly elevated in the plasma of patients with AMI or MI (18). Numerous prospective studies have demonstrated that CRP may independently predict cardiovascular events $(19,20)$, and it therefore has important clinical value in the diagnosis of MI, as well as the diagnosis of ischemic stroke and sudden cardiac death (21). In addition, cTnI has been reported to hold great value in assessing thrombolytic effects, predicting infarct size and identifying unstable angina (22). For instance, Twerenbold et al (23) reported that detection of hypersensitive $\mathrm{cTnI}$ is able to accurately quantify the extent of myocardial damage. Xu et al (24) indicated that the serum levels of hs-CRP and cTnI in patients with AMI were significantly higher than those in healthy controls, and they were significantly lower in the treatment-effective group than in the treatment-ineffective group. Similarly, in the present study, no significant difference in the levels of hs-CRP and cTnI prior to AMI treatment was identified between the two groups; however, after AMI treatment, their levels were significantly lower in the effective group than those in the ineffective group, and it was suggested

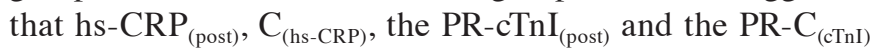
may be used as independent factors to predict early treatment

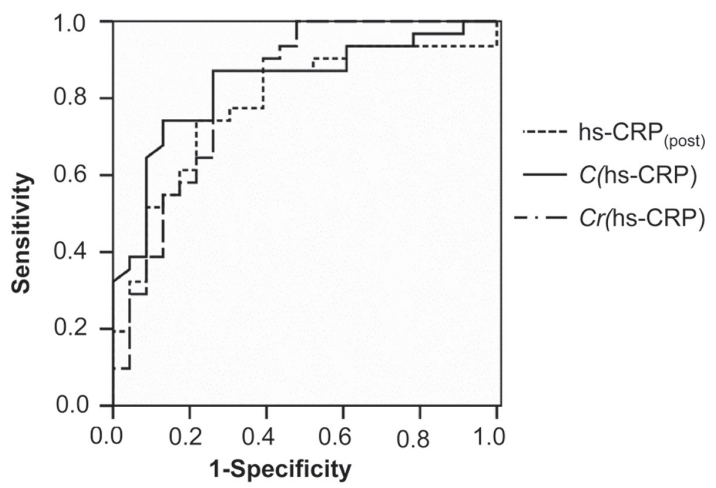

Figure 2. Receiver operating characteristic curves for hs-CRP $\mathrm{Cpost}_{1}, \mathrm{C}(\mathrm{hs}-\mathrm{CRP})$ and $\mathrm{Cr}(\mathrm{hs}-\mathrm{CRP})$ to differentiate between the effective and ineffective groups. hs-CRP, hypersensitive $\mathrm{C}$-reactive protein; $\mathrm{C}$, extent of change; $\mathrm{Cr}$, change rate; post, post-treatment.

outcomes in patients with AMI. Muhlestein et al (25) demonstrated that the change of Erythrocyte Distribution Width was of higher evaluation value for the early efficacy of AMI treatment, which is similar to the methodology used in the current study. Consistently, the present study also indicated the significant differences in the $\mathrm{C}$ and $\mathrm{Cr}$ of hs-CRP and cTnI between the effective group and the ineffective group after AMI treatment, while there were no differences prior to AMI treatment, indicating that these indicators are able to reflect the early therapeutic effect. Simultaneously, there were significant differences in the level of hs-CRP and $\mathrm{cTnI}$ and their positive rates between the effective and ineffective groups. Further analysis suggested that the combined detection of hs-CRP and cTnI and their combined PRs also exhibited significant differences between the effective and ineffective groups. In addition, the multivariate logistic regression analysis revealed that hs-CRP (post) $_{1}, \mathrm{C}_{\text {(hs-CRP) }}$, PR-cTnI $\mathrm{f}_{\text {(post) }}$ and PR- $\mathrm{C}_{(\mathrm{cTnI})}$ may serve as independent factors for evaluating the early response to AMI treatment. Furthermore, the ROC curve analysis of the present study revealed that the AUC, sensitivity and specificity for the $\mathrm{C}$ and $\mathrm{Cr}$ of $\mathrm{cTnI}$ and hs-CRP for evaluating the early treatment efficacy of AMI than those for hs-CRP (post) and $\mathrm{cTnI}_{(\text {post) }}$. In addition, the specificity and sensitivity of the $\mathrm{C}$ and $\mathrm{Cr}$ of $\mathrm{cTnI}$ and hsCRP were better than their absolute values. However, further studies are required to confirm this. 
The present results suggest that introduction of the $\mathrm{C}$ or $\mathrm{Cr}$ of hs-CRP and cTnI in the evaluation of early therapeutic effects in patients with AMI may dynamically reflect early treatment responses, which may further facilitate the development of more individualized and accurate treatments.

At present, complete data on traditional indicators (including AST, LDH and CK-MB) are not available. Thus, it was not possible to compare the utility of modified cTnI and hs-CRP parameters in predicting the efficacy of AMI treatment to that of existing markers (e.g. AST, LDH and CK-MB). However, it has been reported that the diagnostic and prognostic value of cTnI and hs-CRP in patients with AMI is better than that of AST, LDH and CK-MB. For instance, Fan et al (26) demonstrated that the specificity and sensitivity of cTnI in the diagnosis of AMI was much better than that of CK-MB. Jia et al (27) also indicated that cTnI was a better indicator for diagnosis and differential diagnosis of patients with AMI due to its higher sensitivity and specificity compared with that of AST, CK-MB and LDH. Therefore, cTnI may be an ideal biomarker for AMI. In addition, the level of serum cTnI was reported to not be affected by age, sex, site of myocardial damage or thrombolytic drugs (28). Aseri et al (29) suggested that hs-CRP is a more significant predictor for myocardial damage than AST, CK-MB and LDH, and it may be a useful prognostic marker in acute coronary syndrome. In the clinic, the indicators used to evaluate early treatment effects in patients after AMI include, but are not limited to, cTnI, hs-CRP, AST, LDH and CK-MB $(13,14,24)$. However, to the best of our knowledge, no previous study has directly compared the role of cTnI and hs-CRP in evaluating treatment efficacy to that of other traditional indicators (including AST, LDH and CK-MB), and therefore, further studies are warranted.

Of note, the present study has certain limitations. First, the acquisition time of cTnI and hs-CRP data in certain patients did not meet the requirements set by the experimental design, resulting in data loss. Second-treatment duration times were different among each patient, lowering the reliability of conclusion. Furthermore, the overall sample size was relatively small. In addition, the follow-up was relatively short, and the amount of patients lost to follow-up was relatively high, thus the role of hs-CRP and cTnI in evaluating the long-term efficacy of AMI treatment was not determined. Finally, comorbidities in the patients with AMI were not analyzed in the present study. In some AMI patients with comorbidities, the hs-CRP and cTnI values may be altered, which could impact the evaluation of these parameters. Further studies are therefore warranted.

At present, the levels of hsCRP and cTnI are frequently used in the clinic to evaluate the early treatment efficacy of AMI; however, less attention is paid to their changes prior to and after treatment. The present study indicated that the value of the $\mathrm{C}$ and $\mathrm{Cr}$ of hsCRP and cTnI in the evaluation of the early therapeutic efficacy of AMI treatment is improved compared with that of the absolute values, providing a reference for their clinical application.

\section{Acknowledgements}

Not applicable.

\section{Funding}

The present study was supported by the 2017 Key Project of the Chongqing Health Economics Association (grant. no. YWJK2017-1).

\section{Availability of data and materials}

All data generated or analyzed during this study are included in this published article.

\section{Authors' contributions}

LW, BL, MZ, XC and KH designed the study. BL, JY and LC collected and analyzed the data. LW and MZ prepared the manuscript. LL, JY and MZ performed the statistical analysis. LW, JY and KH searched the literature. MZ collected the funds. All authors read and approved the final manuscript.

\section{Ethics approval and consent to participate}

The present study was approved by the Ethics Committee of the Chongqing Health Economics Association (Chongqing, China). Informed consent was obtained from each patient.

\section{Patient consent for publication}

Not applicable.

\section{Competing interests}

The authors declare that they have no competing interests.

\section{References}

1. Reed GW, Rossi JE and Cannon CP: Acute myocardial infarction. Lancet 389: 197-210, 2017.

2. Yu J, Wang L, Peng Y, Xiong M, Cai X, Luo J and Zhang M: Dynamic monitoring of erythrocyte distribution width (RDW) and Platelet Distribution Width (PDW) in treatment of acute myocardial infarction. Med Sci Monit 23: 5899-5906, 2017.

3. Raskovalova T, Twerenbold R, Collinson PO, Keller T, Bouvaist H, Folli C, Giavarina D, Lotze U, Eggers KM, Dupuy AM, et al: Diagnostic accuracy of combined cardiac troponin and copeptin assessment for early rule-out of myocardial infarction: A systematic review and meta-analysis. Eur Heart J Acute Cardiovasc Care 3: 18-27, 2014.

4. Ramesh G, Sai NVB, Gururaj P, Bhupal R and Patel N: Association of metabolic syndrome and level of hs-CRP, Lp(a), and serum ferritin in young Asian patients ( $\leq 45$ years) with acute myocardial infarction. Interv Med Appl Sci 10: 65-69, 2018.

5. Yoshinaga R, Doi Y, Ayukawa K and Ishikawa S: High-sensitivity $C$ reactive protein as a predictor of inhospital mortality in patients with cardiovascular disease at an emergency department: A retrospective cohort study. BMJ Open 7: e015112, 2017.

6. Li J, Wang L, Wang Q, Xin Z, Liu Y and Zhao Q: Diagnostic value of carotid artery ultrasound and hypersensitive C-reactive protein in Type 2 diabetes mellitus patients with acute myocardial infarction in Chinese population. Medicine (Baltimore) 97: e12334, 2018.

7. Yip HK, Wu CJ, Chang HW, Yang $\mathrm{CH}$, Yeh KH, Chua S and $\mathrm{Fu} \mathrm{M}$ : Levels and values of serum high-sensitivity C-reactive protein within 6 hours after the onset of acute myocardial infarction. Chest 126: 1417-1422, 2004.

8. Koskinas KC, Zaugg S, Yamaji K, García-García HM, Taniwaki M, Klingenberg R, Moschovitis A, Lüscher TF, van Tits LJ, Matter CM, et al: Changes of coronary plaque composition correlate with C-reactive protein levels in patients with ST-elevation myocardial infarction following high-intensity statin therapy. Atherosclerosis 247: 154-160, 2016. 
9. Blomström-Lundqvist C, Scheinman MM, Aliot EM, Alpert JS, Calkins H, Camm AJ, Campbell WB, Haines DE, Kuck KH, Lerman BB, et al: ACC/AHA/ESC guidelines for the management of patients with supraventricular arrhythmias-executive summary. A report of the American college of cardiology/American heart association task force on practice guidelines and the European society of cardiology committee for practice guidelines (writing committee to develop guidelines for the management of patients with supraventricular arrhythmias) developed in collaboration with NASPE-Heart Rhythm Society. J Am Coll Cardiol 42: 1493-1531, 2003.

10. Gao RL: Guidelines for the diagnosis and treatment of acute myocardial infarction. Chin J Cardiol 29: 710-725, 2001.

11. Swirski FK and Nahrendorf M: Leukocyte behavior in atherosclerosis, myocardial infarction, and heart failure. Science 339: 161-166, 2013.

12. Mackman N: Triggers, targets and treatments for thrombosis Nature 451: 914-918, 2008

13. Baars T, Neumann U, Jinawy M, Hendricks S, Sowa JP, Kälsch J, Riemenschneider M, Gerken G, Erbel R, Heider D and Canbay A: In acute myocardial infarction liver parameters are associated with stenosis diameter. Medicine (Baltimore) 95: e2807, 2016.

14. Sun T, Zhang L, Li X, Chen F, Li Y, Ma X and Yu F: MicroRNA-1 and circulating microvesicles mediate the protective effects of dantonic in acute myocardial infarction rat models. Front Physiol 9: 664, 2018.

15. Elsman P, Zijlstra F, Miedema K, Hoorntje JC, Dikkeschei LD, Slingerland RJ, Reiffers S, de Boer MJ and Suryapranata H: The predictive value of cumulative lactate dehydrogenase release within the first $72 \mathrm{~h}$ of acute myocardial infarction in patients treated with primary angioplasty. Ann Clin Biochem 41: 142-148, 2004.

16. Young I and Rifai N: High-sensitivity C-reactive protein and cardiovascular disease. Clin Chem 55: 201-202, 2009

17. Cichota LC, Moresco RN, Duarte MM and da Silva JE: Evaluation of ischemia-modified albumin in anemia associated to chronic kidney disease. J Clin Lab Anal 22: 1-5, 2008.

18. Ridker PM,Cushman M,StampferMJ,Tracy RP and Hennekens CH: Inflammation, aspirin, and the risk of cardiovascular disease in apparently healthy men. N Engl J Med 336: 973-979, 1997.

19. Dibra A, Mehilli J, Schwaiger M, Schühlen H, Bollwein H, Braun S, Neverve J, Schömig A and Kastrati A: Predictive value of basal C-reactive protein levels for myocardial salvage in patients with acute myocardial infarction is dependent on the type of reperfusion treatment. Eur Heart J 24: 1128-1133, 2003.

20. Suleiman M, Khatib R, Agmon Y, Mahamid R, Boulos M, Kapeliovich M, Levy Y, Beyar R, Markiewicz W, Hammerman H and Aronson D: Early inflammation and risk of long-term development of heart failure and mortality in survivors of acute myocardial infarction predictive role of C-reactive protein. J Am Coll Cardiol 47: 962-968, 2006.
21. Stumpf C, Sheriff A, Zimmermann S, Schaefauer L, Schlundt C, Raaz D, Garlichs CD and Achenbach S: C-reactive protein levels predict systolic heart failure and outcome in patients with first ST-elevation myocardial infarction treated with coronary angioplasty. Arch Med Sci 13: 1086-1093, 2017

22. Zhang XG, Wang NS and Gao XP: Risk factors for cardiovascular disease in patients with chronic kidney disease. J Clin Kidney Dis 10: 220-222, 2010.

23. Twerenbold R, Boeddinghaus J, Nestelberger T, Wildi K, Rubini Gimenez M, Badertscher P and Mueller C: Clinical use of high-sensitivity cardiac troponin in patients with suspected myocardial infarction. J Am Coll Cardiol 70: 996-1012, 2017

24. Xu GX, Wang F and Yang YQ: Clinical significance of detection of plasma LP (a) Hcy hs-CRP and cTnI levels in patients with acute myocardial infarction. Int J Laboratory Med: 2466-2468, 2014.

25. Muhlestein JB, Lappe DL, Anderson JL, Muhlestein JB, Budge D, May HT, Bennett ST, Bair TL and Horne BD: Both initial red cell distribution width (RDW) and change in RDW during heart failure hospitalization are associated with length of hospital stay and 30-day outcomes. Int J Lab Hematol 38: 328-337, 2016.

26. Fan J, Ma J, Xia N, Sun L, Li B and Liu H: Clinical value of combined detection of CK-MB, MYO, cTnI and plasma NT-proBNP in diagnosis of acute myocardial infarction. Clin Lab 63: 427-433, 2017.

27. Jia CY, Wang L, Mao ZG, Zhang JL and Zhang L: Combined myocardial injury markers for diagnosis of acute myocardial infarction. Sichuan Da Xue Xue Bao Yi Xue Ban 40: 1082-1085, 2009 (In Chinese).

28. Vogiatzis I, Dapcevic I, Datsios A, Koutsambasopoulos K, Gontopoulos A and Grigoriadis S: A comparison of prognostic value of the levels of ProBNP and troponin T in patients with Acute Coronary Syndrome (ACS). Med Arch 70: 269-273, 2016.

29. Aseri ZA, Habib SS, Alhomida AS and Khan HA: Relationship of high sensitivity C-reactive protein with cardiac biomarkers in patients presenting with acute coronary syndrome. J Coll Physicians Surg Pak 24: 387-391, 2014.

This work is licensed under a Creative Commons Attribution-NonCommercial-NoDerivatives 4.0 International (CC BY-NC-ND 4.0) License. 